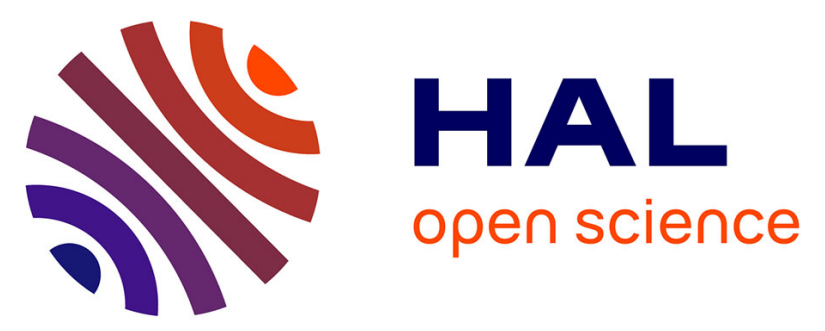

\title{
Contribution of the New satellites (Sentinel-1, Sentinel-2 and SPOT-6) to the Coastal Vegetation Monitoring in the Pays de Brest (France)
}

Halima Talab Ou Ali, Simona Niculescu, Vanessa Sellin, Christophe Bougault

\section{- To cite this version:}

Halima Talab Ou Ali, Simona Niculescu, Vanessa Sellin, Christophe Bougault. Contribution of the New satellites (Sentinel-1, Sentinel-2 and SPOT-6) to the Coastal Vegetation Monitoring in the Pays de Brest (France). SPIE DIGITAL LIBRARY, 2017, Remote Sensing for Agriculture, Ecosystems, and Hydrology XIX, 10421 (1042129), 17 p. 10.1117/12.2277320 . hal-01654978

\section{HAL Id: hal-01654978 \\ https://hal.science/hal-01654978}

Submitted on 4 Dec 2017

HAL is a multi-disciplinary open access archive for the deposit and dissemination of scientific research documents, whether they are published or not. The documents may come from teaching and research institutions in France or abroad, or from public or private research centers.
L'archive ouverte pluridisciplinaire HAL, est destinée au dépôt et à la diffusion de documents scientifiques de niveau recherche, publiés ou non, émanant des établissements d'enseignement et de recherche français ou étrangers, des laboratoires publics ou privés. 


\title{
Contribution of the New satellites (Sentinel-1, Sentinel-2 and SPOT-6) to the Coastal Vegetation Monitoring in the Pays de Brest (France)
}

\author{
Talab-Ou-Ali Halima ${ }^{a}$, Niculescu Simona ${ }^{a}$, Sellin Vanessa ${ }^{b}$, Bougault Christophe ${ }^{b}$ \\ ${ }^{a}$ LETG Laboratory, Technopôle Brest-Iroise, 29280 Plouzané Cedex5 \\ ${ }^{\mathrm{b}}$ CNB Brest, 52 Allée du Bot, 29200 Brest
}

\begin{abstract}
This paper presents a methodology for monitoring vegetation in the Pays de Brest using new series of Sentinel-1 satellite images combining with Sentinel-2 and SPOT-6. This work consists of establishing an interferogram method of the main types of vegetation in order to achieve the coherence of a multi-temporal Sentinel-1 radar image series, in SLC format (C band, VV and VH polarization), between 2015 and 2016. We then proceed to calculating the radar backscatter coefficient based on Sentinel 1 images in GRD format. Multi-date and multipolarized color compositions will be made to detect changes. It also shows the importance of data synergy to obtain an excellent accuracy using Random Forest classification..
\end{abstract}

Keywords: Remote sensing, temporal monitoring, Synergy, Sentinel-1, Sentinel-2, SPOT-6, classification, vegetation.

\section{1- INTRODUCTION}

During this last decade, optical remote sensing images of Very High Spatial Resolution (VHSR) have provided new impetus for vegetation monitoring and mapping due to the very detailed and accurate information recorded. Nevertheless, optical data analyses were rapidly hindered by the presence of the cloud cover in most images available for la Bretagne. Since 1991 however, this problem was solved by the first ERS-1 synthetic aperture radar, the new remote sensing images of which have complemented the old datasets. The signal intensity of the new devices is little disturbed by the atmosphere and the clouds.

This is the background against which our paper is set, which is aimed at suggesting a new vegetation monitoring and mapping methodology applicable to the Pays de Brest. It is based on the use of a temporal series of images recorded by Sentinel-1 radar sensors in the Pays de Brest, between 2015 and 2016.

This is a highly topical research theme due to the revolution brought about by the series of Sentinel 1 and 2 satellite images in the satellite sensor program. Our paper uses Sentinel 1 satellite images. For the first time, Sentinel-1 images combine high spatial resolution $(\sim 10 \mathrm{~m})$ and high temporal frequency ( 6 days), thus allowing more reliable monitoring over time.

The first objective of this paper is to describe the different findings of several radar interferometry processing methods used to determine the interferometric coherence of S1 satellite images and radar backscatter coefficient on each date considered, in order to achieve temporal evolution charts for 2015 and 2016. In fact, radar interferometry is a technique based on the generation of an interferogram relying on two complex images of the same area, images recorded on two different occasions. Thus, it allows studying any changes in the state of the ground surface, which are shown by ground backscatter property changes. Vegetation, in particular, evolves rather rapidly, which accounts for the importance of the Sentinel 1 temporal series for the temporal monitoring of these changes. At the same time, the polarimetric method used to calculate the radar backscatter coefficient also allows monitoring backscatter changes in the target areas.

The second objective is to map the vegetation in the Pays de Brest by combining this set of Sentinel-1 radar images with the Sentinel-2, SPOT6 and 7 optical images.

\section{State of the Art}

Numerous research papers have shown the contribution of remote sensing data to vegetation monitoring and mapping at different spatial and temporal scales. Radar images are used by means of different polarimetry and interferometry calculation methods. 
Contribution of Sentinel-1 Satellite Images to Vegetation Monitoring 2

Gosselin (Gosselin et al., 2014) has worked with RADASRSAT-2 and ALOS-PALSAR polarimetric data in order to study plant physiognomies in the wetlands around the Canadian lake of Saint-Pierre. His research relied on Touzi decomposition used to characterize and classify the plant physiognomies in the wetlands around the Canadian lake of Saint-Pierre. This method is based on the incoherent decomposition of the characteristics of the coherence matrix, which allows distinguishing among classes by the backscatter parameter thresholding method. Fieuzal (Fieuzal, 2013) used the same RADARSAT- 2 data combined with the Terrasar-X data in order to estimate the biophysical parameters of the agricultural areas of the "South-East" CESBIO work area located in the vicinity of Toulouse. His research revealed the strong complementarity of the multi-sensor/multi-spectral approach during the phonological cycle of the researched crops (wheat, rape, corn, sunflower and soy). He detected specific behaviors of the backscatter coefficients towards the various crops, for the $\mathrm{X}$ and $\mathrm{C}$ or $\mathrm{L}$ bands. Indeed, the $\mathrm{X}$ band with $\mathrm{HH}$ polarization seems reliable for wheat monitoring, whereas rape and corn have shown interesting dynamics in the $\mathrm{C}$ band with cross polarization (VH or HV). Finally, the different polarizations in the $\mathrm{C}$ band reveal reliable variations for sunflower and soy monitoring.

Interferometric coherence helps classifying the different types of diffusers (Pottier and Cloude, 1997). It is used to characterize plant cover and biomass (Strozzi et al., 2000). It was also used by (Floury et al., 1997) to distinguish between forest areas and non-forest areas, and also to calculate the biophysical forest parameters in the Landes area in Southern France. (Prakoso, 2003), used this technique to map the tropical areas of the Tapajõs forest in Brazil, for which he preferred images recorded in L band $(\square 23 \mathrm{~cm})$ and in P band $(\square 1 \mathrm{~m})$. Pathier's latest work (PATHIER, et al., 2017) relied on ALOS-2 and Sentinel-1 satellite images and consisted of slow earthquake research by satellite radar interferometry in the Mexican subduction area. Interferometry data are used in their work to complement GPS earthquake findings.

Temporal monitoring is one of the advantages of the backscatter image series. Baghdadi et al. (Baghdadi et al., 2012) monitored sugar cane harvesting by means of multi-temporal Terrasar-X satellite images recorded at different incidence angles $\left(31^{\circ}, 37^{\circ}, 47^{\circ}\right)$ and polarizations $(\mathrm{HH}, \mathrm{HV}, \mathrm{VV}$ in the Réunion Island in the western part of the Indian Ocean. This research has proven that backscattered radar signal increases quickly with the sugar cane height up to a height threshold, which depends on the incidence angle and polarization. Other works may also be quoted for crop monitoring: (Guerriero et al., 2013) studied radar backscatter in VV, HV and HH polarization, in L and $\mathrm{C}$ bands, according to the TOV pattern, which was selected for predicting the bistatic scatter coefficient of crops. It relies on the radiative transfer theory and it prefers a discrete approach in which the vegetation elements are described as discrete dielectric diffusers and appropriate electromagnetic theories are used to calculate their absorption and diffusion cross sections. For their part, (Inoue et al., 2014) studied the backscatter parameters in C band of rice crops and proved the importance of the backscatter radar signal for assessing LAI and FAPAR parameters used to monitor rice growth. Also in relation to that, (Hosseini et al., 2015) used polarimetric data in C and L band in order to determine the LAI parameter of crops. They concluded that $\mathrm{C}$ band may be used to determine LAI on corn and soy fields. As concerns the $\mathrm{L}$ band, it is more reliable for corn crops. They also showed that cross polarizations are more accurate for LAI determination than parallel polarizations.

Sentinnel-1 series are dense and guaranteed temporal series, with extended coverage and fine resolution. Several research works were presented during the $4^{\text {th }}$ PNTS Thematic Day on 24 March 2016, called "Contributions of SentinelCopernicus Missions to Earth Observation”. A. Bouvet (CESBIO, Toulouse) described vegetation monitoring. These works dwelt on several types of monitoring, namely: temporal monitoring of the radar backscatter coefficient in $\mathrm{C}$ band in cross polarization for the surveillance of forests threatened by deforestation, whether it is early deforestation detection, or tree cutting in managed forests. As concerns crops, the VV/VH polarization ratio is strongly correlated with the NDVI vegetation index read by optical sensors. Another similar study monitoring rice fields revealed that here the temporal backscatter change was higher. Torbick et al. (Torbick et al., 2017) also used the radar backscatter coefficient of the S1 series to monitor rice crops in order to map the rice growing areas of Myanmar, in South-Eastern Asia, their cropping calendar, flooding and crop intensification. Pathier et al also showed the high importance of high spatial resolution of the Sentinel-1 series. Indeed, the transition from 24 to 12 days significantly improves the signal in poor coherence areas. Consequently, spatial resolution will be more significant due to the combination of Sentinel-1 A and S-1 B data. Frison 
Contribution of Sentinel-1 Satellite Images to Vegetation Monitoring 3 et al. 2017 studied the relation between the two VV and VH polarizations of Sentinel-1 data in order to achieve better seasonality, with approximately $5 \mathrm{~dB}$ amplitude. The signal increases at the beginning of March, remains high until September, then starts to decrease at the end of September and drops down to its minimum at the end of November. These findings, in phase with NDVI, prove that the polarization ratio is completely related to the foliar activity period. (Frison et al., 2017).

Soil humidity impedes on the radar signal (Ulaby et al., 1986). This sensitivity decreases with the increase of the incidence angle (Dissanska m. et al 2010). Baghdadi (baghdadi et al) also showed that the radar signal is highly dependent on this humidity, especially at lower and medium incidence angles $\left(31^{\circ}\right.$ and $\left.37^{\circ}\right)$, unlike images recorded at high incidence angles $\left(47^{\circ}\right)$.

In the optical field, the SPOT 6 satellite brought about considerable spatial resolution improvements. This good resolution makes this satellite perfect for herbaceous area detection. Indeed, it provides an interesting alternative to the traditional methods based on air and ground image analysis (Oumar, 2016). Nevertheless, despite this technical breakthrough, the SPOT satellite images are not always accurate. When vegetation is characterized by spatial complexity (patchwork like), classifications are not accurate. High spatial resolution data allow to partially solve this problem, yet it is still a challenge when extended areas are studied (Bartsch et al., 2016). SPOT 5 satellite data were compared to Sentinel-2 and Landsat- 8 data in a study about the detection of objects smaller than one pixel (Radoux et al., 2016). The findings showed that the spectral resolution of SPOT 5 renders it considerably less reliable than the other two satellites for this type of analysis. SPOT 6 and 7 do not enjoy major changes in terms of spectral resolution, which allows us to conclude that they are less reliable than Sentinel-2 for the detection of objects smaller than one pixel. Therefore, this will negatively influence the accuracy of the classification, especially if the image is made up of numerous mixed pixels.

Sentinel-2 images were compared on many occasions and the possible contributions of this new sensor were therefore defined. To start with, separability was found to be relatively good thanks to this sensor. Separability is the ability to distinguish between foreground and background classes (Radoux et al., 2016). Thus, thanks to this type of input data, it is possible to reveal the different classes present in a mixed pixel. The classifications achieved based on these Sentinel-2 data are therefore more accurate and of higher quality than those based on Landsat- 8 data, for instance (Topaloglu et al., 2016). Certain spectral bands are truly added value: the three "red-edge" bands and the SWIR band (short infrared). The "red-edge" bands allow distinguishing between vegetation types and status. These nuances are particularly helpful for specific applications. The short infrared band is relatively important for grassy area detection (Radoux et al., 2016). Furthermore, the combination of 2 (blue), 5 (red-edge 1) and 11 (SWIR 1) spectral bands has proven to be extremely interesting for crop and tree classification. Finally, a vegetation study (Immitzer et al., 2016) claims that the green band is the weakness of Sentinel-2. Indeed, the other bands that were not considered here are useful in different fields. A five-day temporal resolution with Sentinel-2A and Sentinel-2B is vital for a more accurate species determination. Multi-temporal image analysis will allow viewing phenological variations in such a way as to enable the best species classification possible (Vaglio et al., 2016). Nonetheless, the spatial resolution of Sentinel-2 is not good enough to allow the delimitation and classification of isolated individuals (individual trees, detailed patchwork of different species) (Stratoulias et al., 2015). It would therefore be useful to consider together data on vegetation texture or vertical structure (LiDAR data) in order to compensate the negative effects related to spatial resolution (Vaglio et al., 2016). In fact, the combination of a significant spectral resolution and of a relatively good spatial resolution allows Sentinel-2 to produce better results than SPOT 6/7 or even Landsat-8.

Whereas multi-spectral optical images allow distinguishing between different lithologies based on their spectral signatures, radar images, due to their high sensitivity to surface roughness, are rather appropriate for structural mapping. Therefore, the radar/optical synergy play a very important role in the creation of an image which combines the two types of information.

We refer here to Dusseux's work on radar/optical synergy (Dusseux, 2014), who managed to distinguish grasslands from other crops in agricultural areas and to identify their management techniques by means of series of SPOT-4, RADARSAT-2 images. He carried out preprocessing and processing of these series of images in order to generate 
Contribution of Sentinel-1 Satellite Images to Vegetation Monitoring 4 parameters such as vegetation indices, biophysical variables, radar parameters (polarimetric decompositions and intensities). He was also able to show the relation between LAI derived from optical images and VV backscatter coefficient resulting from radar data. This study supports the combination of an optical series and of a radar series, which allows distinguishing grasslands from crops. Niculescu's work (Niculescu et al., 2016) on plant structure recognition in wetlands relied on optical (SPOT-5) radar (RADARSAT-2) and LiDAR data, the goal being the generation of a very fine vegetation classification in the Danube Delta. They showed that data synergy is dependent on vegetation classes. Indeed, RADAR alone allows detecting dune forests, whereas optical data can detect dune vegetation and reed. As far as classification is concerned, the best fusion for all the classes under survey is the LIDAR/ Optical data combination.

Mapping classification is a method which allows assigning a class to each spatial unit based on its signature (Cano, 2016). Thus, a distinction is possible between pixel-based classification and object-oriented classification. Pixel-based classification is most commonly used in vegetation research. This classification relies on two methods: supervised classification and non-supervised classification. Non-supervised classification is a classification made directly by the software. The software classifies pixels according to their spectral signature in groups the number of which was predetermined. Similarly, supervised classification is preceded by the identification of pixels the nature of which is known. These pixels, called "practice" pixels, will allow the software to classify the whole set of pixels according to the spectral signature of practice pixels (Jones \& Vaughan, 2010).

It is necessary to choose a supervised classification algorithm. Parameter algorithms only apply to supervised perpixel classification. Therefore, they are only reliable if the distribution of the pixels within a class observes the Gaussian distribution (Cano, 2016). Finally, they are hard to use with multi-temporal data the spectral characteristics of which vary (Gomez et al, 2016). Maximum likelihood or Minimum Likelihood Classification (MLC) is a parameter algorithm which assigns a class to a pixel according to a probable affiliation value (Cano, 2016). Non-parameter algorithms such as Support Vector Machines (SVM) or Random Forest (RF) require the definition of initial parameters; however, spectral pixel signature distribution does not influence the processing. SVM (Cortes \& Vapnik, 1995) is based on an automatic learning principle. It determines a classification by comparison to the practice pixels, which it subsequently applies to the whole pixel population (Cano, 2016). One strength of this algorithm is the fact that it is not sensitive to the Hughes phenomenon, that is the number of elements does not impede on the accuracy of the method (Gomez et al., 2016). The RF algorithm (Breiman, 2001) often provides more accurate classifications than the other algorithms and it is able to process complex data from the spatial and spectral points of view. The latter relies on class separation based on decision trees, with a view to achieving the most homogeneous classes, which are then applied to the image for classification purposes. Algorithm combination tends to increase classification accuracy but also to reduce the interoperability of the findings (Gomez et al., 2016).

\section{2- PRESENTATION OF THE RESEARCHED AREA}

The Le Pays de Brest is an association of communes lying in the northern part of the Finistere Department in mainland France (Figure 1). It is organized around the Brest urban center where most businesses and employments in the Pays de Brest are found. The quality and diversity of its landscapes together with its $350 \mathrm{~km}$ of seafront give the Pays de Brest its patrimonial interest, which accounts for the various management decisions to be made. 


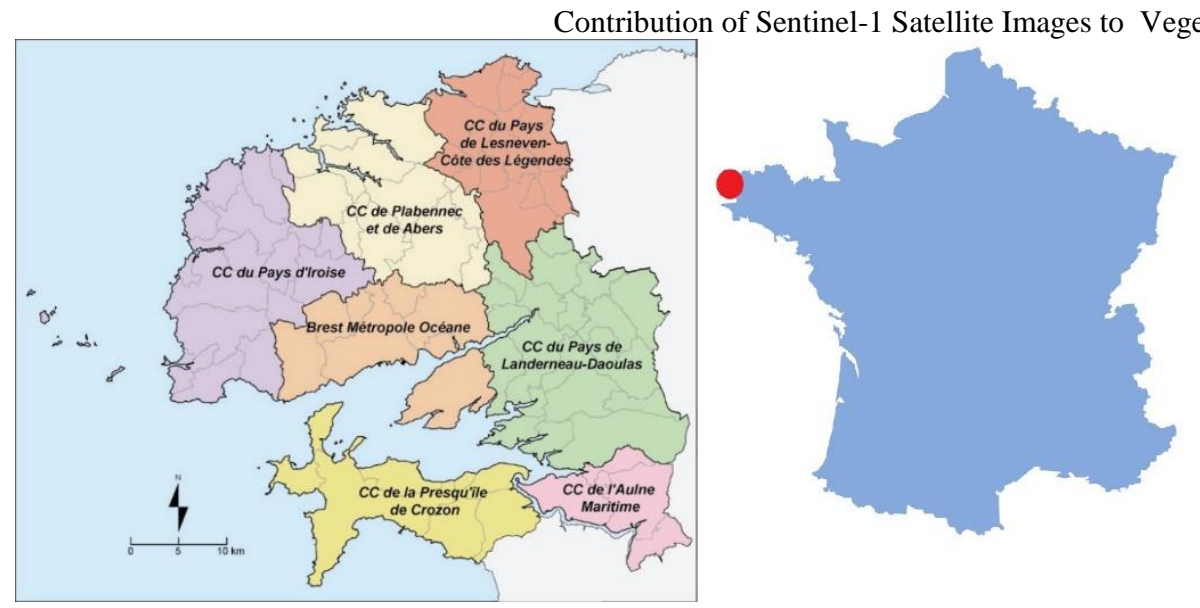

Figure 1: Pays de Brest Geographical Area

The vegetation classes were chosen by photo interpretation based on SPOT 6 images and based on the in situ data from the Brest National Botanical Conservatory $(\mathrm{CBN})$. Field visits also enabled us to check the classes and update the height information for certain plots. We also used the latest maps created by the CESBIO1 research center in 2016 based on Sentinel 2 and Landsat-8 images for mainland France. These data enabled us to define the land cover classes that will be studied in our research. Only the classes visible on the optical images were considered. Certain classes were, for their part, regrouped. Finally, we decided to work with 14 classes (types of vegetation):

1- Forest class,

2- Grassland class,

3- Undergrowth class,

4- Summer crop class,

5- Winter crop class,

6- Moor class,

7- Tree plantation class,

8- Park and garden class

9- Lawn and dune class,

10- Salt marsh class,

11- Hedge and embankment class,

12- Reed bed class,

13- Seaweed field class,

14- Vegetation-free class (which includes buildings, rocks, cliffs and everything else that lacks vegetation).

These classes will allow studying the temporal monitoring of the types of selected vegetation and also classifying them by data synergy. Therefore, the first work consists of establishing the contribution of the Sentinel-1 series to the monitoring of the temporal evolution of these classes in VV and $\mathrm{VH}$ polarization, and also of determining their relation to ground humidity by means of precipitations. Then, the second work dwells on the study of the contribution of the combination of Sentinel-1 and Sentinel-2 images and SPOT6/7 data to vegetation mapping.

\footnotetext{
${ }^{1}$ Spatial Research and BIOsphère Center of Toulouse.
} 


\section{Contribution of Sentinel-1 Satellite Images to Vegetation Monitoring 6}

3- SPATIAL DATA USED

\subsection{Satellite Data}

\section{SAR Data}

The SAR (Synthetic Aperture Radar) satellites called Sentinel-1 A and B were put in orbit on 3 April 2014 and 25 April 2016, respectively. The constellation of these two satellites was developed by the European Spatial Agency (ESA) in the Copernicus Program, and they resumed and continued the work of the ERS and ENVISAT satellites. The program was developed in order to provide European countries with complete and updated data in C band $(5.6 \mathrm{~cm})$, which would allow them to ensure environmental surveillance. The orbit of the two satellites is quasi-polar, with a 12-day temporal resolution, which would ultimately allow the survey of the same geographical area every 6 days.

The Sentinel-1 images are available in SLC (Single Look Complex) or GRD (Ground Range Detected) format and in several acquisition modes. For our research, we preferred the Interferometric Wide swath (IW), a mode in which the images are recorded according to a $250 \mathrm{~km}$ scan swath and $5 \mathrm{~m} * 20 \mathrm{~m}$ spatial resolution. This mode is made up of three sub-swaths: IW1, IW2 and IW3, which correspond to cyclical antenna deviations recorded by means of the TOPSAR (Terrain Observation with Progressive Scans SAR) technique.

The images available are in VV parallel and VH cross polarization. VV is what we called the co-polar channel: the backscattered wave has the same polarization as the emitted wave, i.e. vertical (there is no season-related polarization change). VH is the cross-pole channel, which means that there was a complete modification of the state of polarization when the wave interacts with the environment, i.e. from vertical to horizontal.

22 images in SLC and 40 images in GRD were available for the ascending orbit 103 (Table 1), between the month of May 2015 and the month of October 2016. As far as orbit 154 is concerned, 30 images in SLC and 37 in GRD were available.

Table 1. Sentinel-1 Images Available

\begin{tabular}{|l|l|l|l|l|l|l|}
\hline \multicolumn{9}{|c|}{ Sentinel-1 } \\
\hline $\begin{array}{l}\text { Type of } \\
\text { image }\end{array}$ & Orbit & Type of orbit & $\begin{array}{l}\text { Angle of } \\
\text { incidence }\end{array}$ & Polarization & $\begin{array}{l}\text { Acquisition } \\
\text { mode }\end{array}$ & $\begin{array}{l}\text { Number of } \\
\text { images }\end{array}$ \\
\hline \multirow{2}{*}{ SLC } & 103 & Ascending & $38.8^{\circ}$ & & & 22 \\
\cline { 2 - 4 } & 154 & Descending & $38.7^{\circ}$ & \multirow{4}{*}{ VV/VH } & IW & 30 \\
\hline \multirow{2}{*}{ GRD } & 103 & Ascending & $38.7^{\circ}$ & & 40 \\
\cline { 2 - 3 } & 154 & Descending & $38.8^{\circ}$ & & & 37 \\
\hline
\end{tabular}

\section{Optical Data}

SPOT 6/7 data and Sentinel-2 data are the optical data used in our research. The sentinel-2 images are a continuation of the LANDSAT mission with improved spatial and temporal resolutions. This is a high resolution optical mission of the European Space Agency (ESA). The Sentinel-2 satellite is characterized by $786 \mathrm{~km}$ altitude, polar orbit and 5-day cycle with the two satellites A and B. The sentinel-2 A satellite was launched on 23 June 2015, whereas the Sentinel-2 B satellite was launched on 7 March 201. The Sentinel-2 images comprise 13 spectral bands, the resolutions of which are shown in the table hereunder:

Table 2. Spatial and spectral resolutions of the Sentinel2 satellite

\begin{tabular}{|c|c|c|}
\hline Band & $\begin{array}{c}\text { Spectral } \\
\text { resolution }\end{array}$ & Spatial resolution \\
\hline B1 Aerosol & $60 \mathrm{~m}$ & $433-453 \mathrm{~nm}$ \\
B2 Blue & $10 \mathrm{~m}$ & $458-523 \mathrm{~nm}$ \\
\hline
\end{tabular}


Contribution of Sentinel-1 Satellite Images to Vegetation Monitoring 7

\begin{tabular}{|c|c|c|}
\hline B3 Green & $10 \mathrm{~m}$ & $543-578 \mathrm{~nm}$ \\
B4 Red & $20 \mathrm{~m}$ & $650-680 \mathrm{~nm}$ \\
B5 Red-edge 1 & $20 \mathrm{~m}$ & $698-713 \mathrm{~nm}$ \\
B6 Red-edge 2 & $20 \mathrm{~m}$ & $733-748 \mathrm{~nm}$ \\
B7 Red-edge 3 & $10 \mathrm{~m}$ & $765-785 \mathrm{~nm}$ \\
B8 Wide near infrared wide & $20 \mathrm{~m}$ & $785-900 \mathrm{~nm}$ \\
B8a Narrow near infrared & $60 \mathrm{~m}$ & $855-875 \mathrm{~nm}$ \\
B9 Cloud & $60 \mathrm{~m}$ & $930-950 \mathrm{~nm}$ \\
B10 Water vapor & $20 \mathrm{~m}$ & $1365-1385 \mathrm{~nm}$ \\
B11 SWIR1 & $20 \mathrm{~m}$ & $1565-1655 \mathrm{~nm}$ \\
B12 SWIR2 & & $2100-2280 \mathrm{~nm}$ \\
\hline
\end{tabular}

The spot 6 satellite was launched during the third quarter of 2012, spot 7 during the first quarter of 2014, both having a sun-synchronous orbit, a 26-day cycle and $694 \mathrm{~km}$ altitude. The SPOT 6 images include 5 spectral bands, the spatial and spectral resolutions of which are shown in the table below:

Table 3. Spatial and spectral resolutions of the SPOT 6/7 satellite

\begin{tabular}{|c|c|c|}
\hline Band & Spectral resolution & Spatial resolution \\
\hline B1 Blue & $6 \mathrm{~m}$ & $450-520 \mathrm{~nm}$ \\
B2 Green & $6 \mathrm{~m}$ & $530-590 \mathrm{~nm}$ \\
B3 Red & $6 \mathrm{~m}$ & $625-695 \mathrm{~nm}$ \\
B4 Near infrared & $6 \mathrm{~m}$ & $760-890 \mathrm{~nm}$ \\
B5 Panchromatic & $1.5 \mathrm{~m}$ & $450-745 \mathrm{~nm}$ \\
\hline
\end{tabular}

\subsection{Other Data}

Daily precipitation data were used in addition to the Sentinel-1 data. These data were gathered on the NOAA ${ }^{2}$ website, where scientists use high-end tools to provide reliable scientific data. (https://www.ncdc.noaa.gov/)

We also used the database made available by the Brest National Botanical Conservatory (CBN). We also used the latest maps created by the CESBIO3 research center in 2016 based on Sentinel 2 and Landsat-8 images on land cover in mainland France.

\section{4- SATELLITE IMAGE ANALYSIS AND PROCESSING}

We begin our paper by describing the manner in which we calculated the interferograms of the main types of vegetation, the purpose being to attain the coherence of a multi-temporal series of Sentinel-1 radar images, in SLC format (C band, VV and VH polarization), between 2015 and 2016. In a second stage, we suggest calculating the radar backscatter coefficient based on Sentinel 1 images in GRD format. The two calculations are done by using the SNAP software from the ESA. Our approach consists of an analysis of the relations between the state of the different vegetation ecosystems and the radar response, the purpose being the establishment of connections between the physical coherence responses and backscatter coefficients and the vegetation parameters (phenology, structure...), as well as the soil humidity state due to precipitations.

\footnotetext{
${ }^{2}$ National Oceanic and Atmospheric Administration

${ }^{3}$ Spatial Research and BIOsphère Center of Toulouse.
} 


\subsection{Interferometric Coherence and Radar Backscatter Coefficient}

Contribution of Sentinel-1 Satellite Images to Vegetation Monitoring 8

Interferometric coherence is the measurement of the noise of the phase of an interferogram, which depends on the parameters of the sensor (resolution, baseline...) and also on the temporal changes of elementary diffusers (Strozzi et al., 2000). Coherence may be modeled, yet this is a complicated exercise since the model must describe the backscattered surface signal of intensity and phase. Phase signal changes randomly due to elementary diffuser changes caused by seasonal variations (Pulliainen et al., 2003). The coherence image was calculated using the SNAP software designed by the ESA (European Spatial Agency), and it requires two radar images to establish the differences between the two dates. The first image is called the master image, whereas the second is the slave image. The coherence images are achieved after four stages (Figure 2):

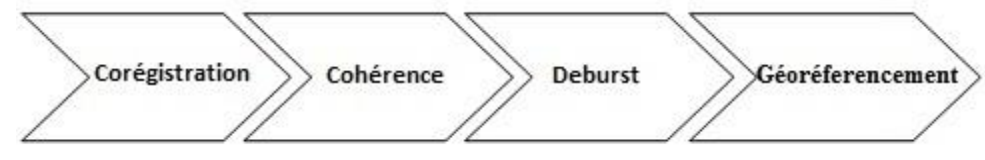

Figure 2. Interferometric Coherence Calculation Stages: 1-Coregistration, 2-Coherence calculation, 3-Debust and 4-Terrain correction (TC)

A radar coregistration stage: it consists of superimposing at the sub-pixel scale the two images of the same scene collected on 2 different dates. This reset is done on the slave image based on orbital files, sensor attitude and MNT (Digital Terrain Model), which is a digital file containing altitude data for the area concerned. Moreover, one of the additional spatial correlations between the 2 images allows improving this reset even more. The findings of this stage provide a picture of the intensity values and of the phases (IW2 which covers the surveyed area).

Once the coregistered image has been obtained, the next step is coherence calculation, which allows the determination of the phase difference on the resulting image. Then, an operation called "deburst" (S1 - TOP) is carried out and it consists of suppressing the black stripes between the image parts recorded in different incidence ranges along the swath.

The last stage is the georeferencing stage called Terrain correction, which allows geometrical distortion correction on the image and achieving a plane geometry, in order to determine the geographical coordinates. The basic image has the spherical geometry of the Earth.

Along with the coherence calculation, we conducted intensity calculations on level 1 (GRD) images, i.e. with impaired spatial resolution caused by an average operation of the radar intensity on a small local neighborhood, in order to reduce the speckle-related radiometric noise. Radiometric calibration is the process which allows determining the backscatter coefficient $\boldsymbol{\sigma 0}$. This methodology is followed by a georeferencing stage.

\subsection{Change Detection by RADAR Imaging}

Season-related change detection is a process which analyzes a pair of images collected in the same geographical area at different moments in time, in order to identify the season-related changes that may have occurred during the two data collection dates. For change detection purposes, several approaches used to map the changes by radar imaging are commonly employed, namely: date 2 .

- By color composites on different dates by using images in intensity: via the color composite: $\mathrm{R}=$ date $1 ; \mathrm{V}$ and $\mathrm{B}=$

- By ineteferometric coherence analysis between 2 images acquired at different moments (Tanase et al., 2010). 
Contribution of Sentinel-1 Satellite Images to Vegetation Monitoring 9 - By calculating temporal means, which are frequently used in temporal radar series.

\section{Temporal Evolution Graphs}

In order to be able to analyze the behavior of the backscatter coefficient values in 2015 and 2016, it is necessary to outline the temporal profile of the mean values in decibels of o 0 throughout the researched area and also in the selected plots (how many plots? in total); the purpose is to find a possible connection between the o 0 values, the seasonal nature of the vegetation and the precipitation data found on the NOAA website.

The temporal evolution graphs are drawn in Python, on QGIS, by using the zonal_stats function, which allows the development of different statistical data (min, max, mean...) on the image according to a given polygon (Algorithm 1). The goal of the entire scripts is to calculate these statistical data on all the images in an automatic manner.

Algorithm 1. Part of the algorithm used for statistical calculations

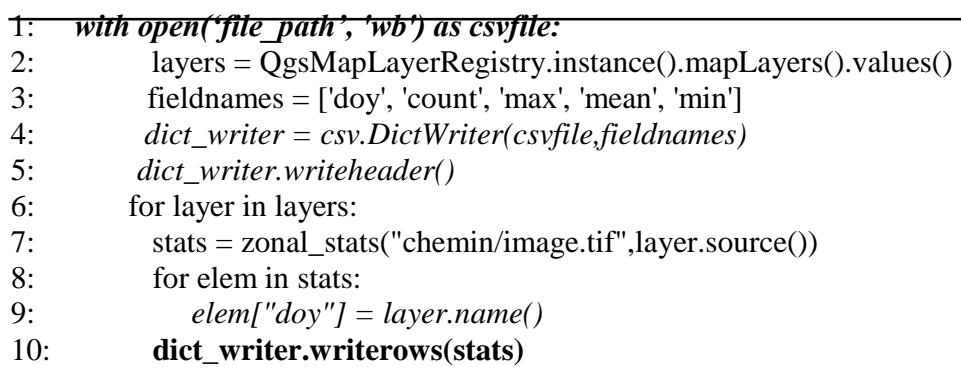

The resulting graphs will be drawn based on average statistical values of the coherence measurements, and based on average statistical values in decibels of the calibration measurements. Therefore, the calibration measurements undergo a decibel conversion according to the following equation (Equation 1): 


\subsection{Supervised Classification}

The Sentinel-2 images contain 14 bands, so we have chosen the bands at $20 \mathrm{~m}$ resolution for classification, bands $\mathrm{B} 2, \mathrm{~B} 3, \mathrm{~B} 4$ and $\mathrm{B} 8$.

The classification method chosen for our study is Random Forest (RF) which is a classification method by ensemble learning using a structured set of decision trees, each tree constituting a single vote for the most popular class of a set Of input data (Rodriguez-Galiano et al., 2012a).

We also compared the results with the maximum likelihood classification method, which is also frequently used in remote sensing (Otukei and Blaschke 2010), to justify our choice of Random Forest. Considering the processing time is longer and requires more time for the Sentinel-1 series, so we compared the classification methods for SPOT-6 and Sentinel-2 optical data.

The maximum likelihood classification on the spot image gave an accuracy of $72.1 \%$, the associated kappa coefficient is 0.71 . For the Sentinel-2 image, precision with the same method gave $76.6 \%$ and the kappa coefficient was 0.70 .

The Random Forest classification, for its part, yielded greater results for the overall accuracy $86.6 \%$ and a kappa coefficient of 0.74 . Classifications by class will be discussed later.

\section{Data Synergy}

There are several methods of image fusion in remote sensing. Whether before or after the classification. The adapted data synergy method is to merge all data before classification. This method is chosen because of the number of exploited images which give us the maximum amont of information. This diagram represents the synergy method adopted. 


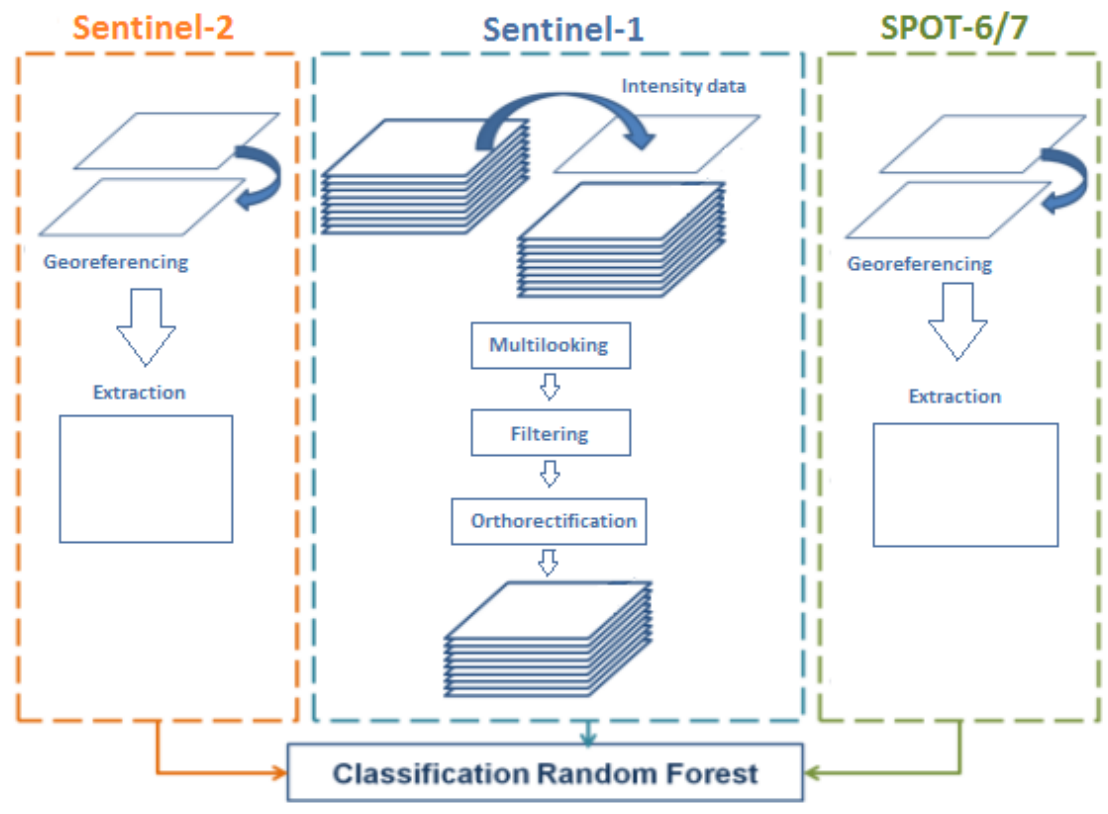

Figure 3 Synergy method between optical and radar data

\section{5- RESULTS AND DISCUSSIONS}

The images resulting from the interferometric coherence calculations and from the radar backscatter coefficient are shown in color composites ( $\mathrm{R}, \mathrm{V}, \mathrm{B})$, in multi-date composition (2 compared dates).

The interferometric calculations made using the Sentinel-1 images enabled us to determine the date on which seasonbased changes were noticed between the two dates, which in our case were 12 days apart. The figure (Figure 4) shows multi-polarization color composites, the red stripe represents the VV parallel polarization and the green and blue stripes represent the VH cross polarization. The first image, which shows the coherence between the 19/07 and 31/07 dates of the year 2015, does not allow establishing a clear season-related change in the area, except for the buildings, which are colored in white in the image (strong coherence); in fact, this is the summer period. On the other hand, the second image (between 06/12/2015 and 18/12/2015) contains more coherence areas, as it depicts the winter period when water may be present on the surface of the plots. The last image depicts the spring period (between 27/03/2016 and 08/04/2016): as one may notice here there are less coherence areas than in the winter period. In the spring, the leaves start to grow, which would account for the inconsistency between the two dates. 


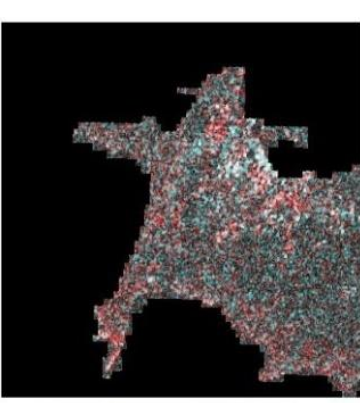

19/07/2015-31/07/2015

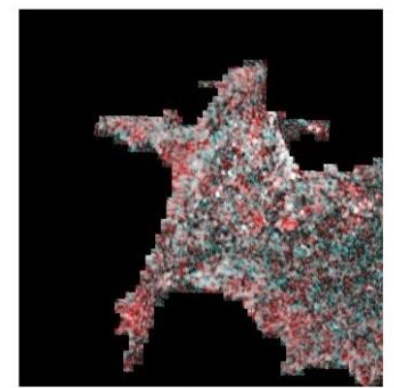

$06 / 12 / 2015-18 / 12 / 2015$

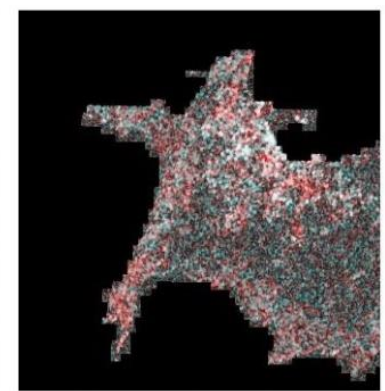

27/03/2016-08/04/2016

Figure 4. Multi-polarization color composite in interferometric coherence $\mathrm{R}=\mathrm{VV}, \mathrm{V}$ and $\mathrm{B}=\mathrm{VH}$ between different dates

As concerns radar polarimetry, the example in the figure (Figure 5) shows a multi-date color composite composition in VH polarization of the radar backscatter coefficient for the two dates 27/01/2016, which represents the winter period, and 11/09/2016, which represents the summer period. The summer crop areas are clearly shown as they are colored in dark red, winter crops are colored in cyan, the grassland areas are darker and the forest areas are a mixture of white and red.

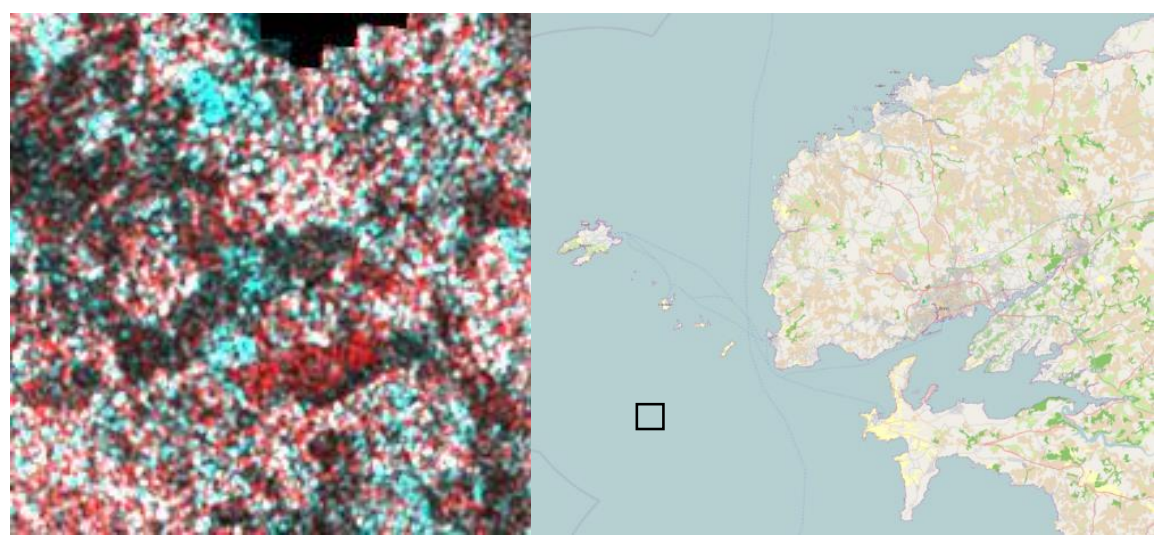

Figure 5. Multi-date color composite $\mathrm{R}=27 / 01 / 2016, \mathrm{~V}$ and $\mathrm{B}=11 / 09 / 2016$ of the radar backscatter coefficient in $\mathrm{VH}$ cross polarization

This is due to the fact that the backscattered signal in $\mathrm{VH}$ cross polarization is not the same as the emitted signal, which adds complementary information as far as radar response is concerned. Thus, the radar images entered based on various polarization and wave length combinations, in VH cross polarization in our case (Figure 5), may provide different and complementary information about the vegetation.

Given the fact that the two orbits we studied (ascending 103 and descending 154) have almost the same angles of incidence (Table 1), the temporal evolution graphs are drawn based on the combinations of the results of the two orbits.

The resulting graphs are obtained by means of the MATLAB statistical software, just like the temporal evolution intensity graph (sigma0 radar backscatter coefficient expressed in decibels) on the first 7 types: moors, forest, undergrowth, grassland, summer crops, winter crops and vegetation-free areas. The first remark would be that the intensity values for the vegetation-free type is stronger than the other classes in VV parallel polarization (values ranging 
Contribution of Sentinel-1 Satellite Images to Vegetation Monitoring 13 between $-8 \mathrm{~dB}$ and $-2 \mathrm{~dB}$, unlike other classes with values ranging between $-18 \mathrm{~dB}$ and $-8 \mathrm{~dB}$ ). On the other hand, for VH cross polarization, the behavior of the signal as far as the building class is concerned oscillates within the same value range as for the other classes. Therefore, for the building class, the VV parallel polarization provides complementary information able to distinguish it from other classes.
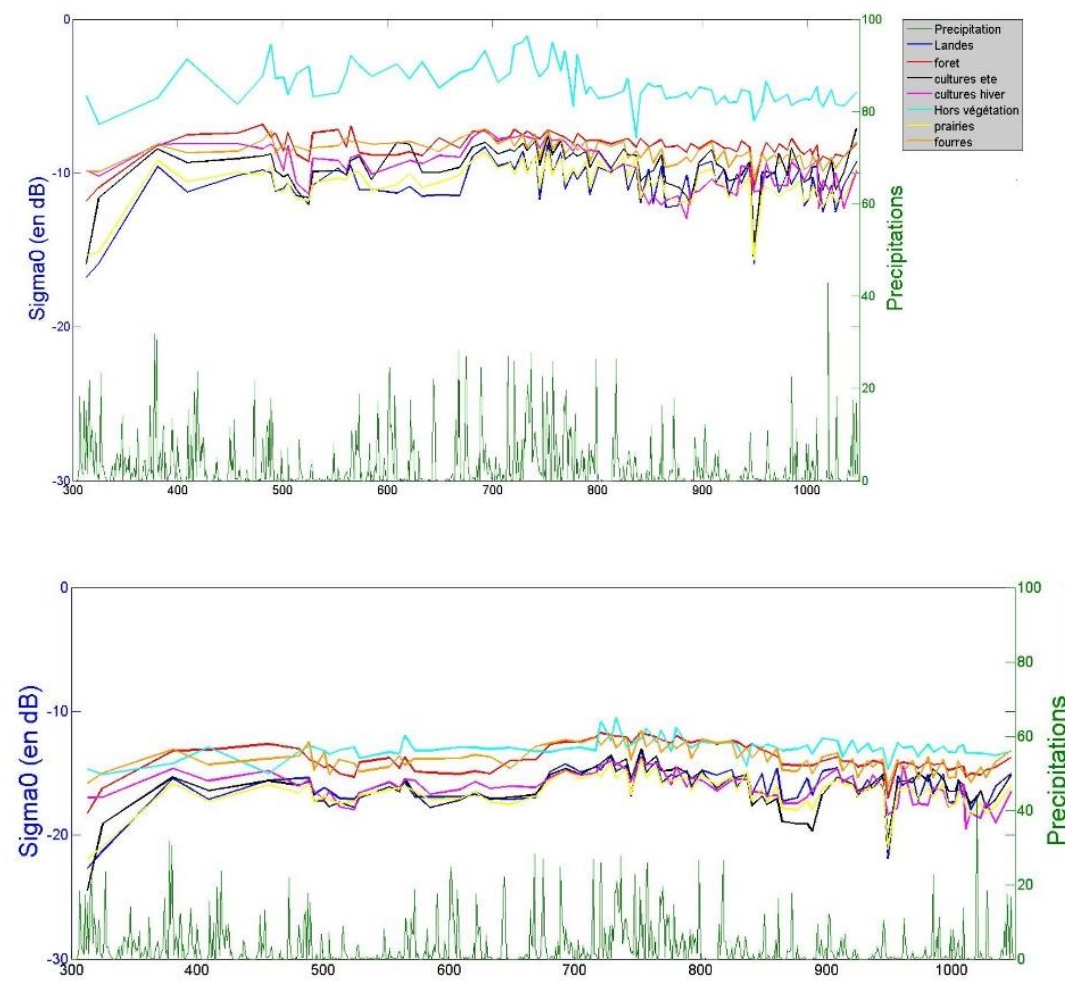

Figure 6. Temporal evolution in VV parallel polarization (top) and in VH cross polarization (bottom) for the radar backscatter coefficient expressed in decibels according to Julian days for the types of moors, forest, undergrowth, grassland, summer crops, winter crops and vegetation-free areas.

The VH polarization values remain inferior to VV polarization values (values ranging between $-30 \mathrm{~dB}$ and $-10 \mathrm{~dB}$ for the $\mathrm{VH}$ polarization and between $-20 \mathrm{~dB}$ and $0 \mathrm{~dB}$ for the VV polarization) (Figure 6 and Figure 7), throughout the analyzed classes.

According to the temporal evolution graphs (Figure 6), precipitations are heavier between December and March, which obviously corresponds to the winter period. On the other hand, one may notice that there are similarly heavy precipitations throughout the year, which is accounted for by the geographical location of the Pays de Brest region. Its specificity consists of the frequent rainfall due to its temperature ocean climate. The region is characterized by cool and wet winters and by mild and relatively wet summers. Moreover, there is a correlation (Figure 6) between the radar signal (sigma0), in VH cross polarization, and the precipitation amounts. This is not the case on the evolution graphs in VV parallel polarization. Furthermore, the diminution of the radar signal for the studied classes could be diminished down to $4 \mathrm{~dB}$ on the images acquired after a rainy period. 
Contribution of Sentinel-1 Satellite Images to Vegetation Monitoring 14

As far as the vegetation types are concerned, we distinguished between winter crops (magenta) and summer crops (black). Winter crops have a more important signal during winter and this signal diminishes during summer.
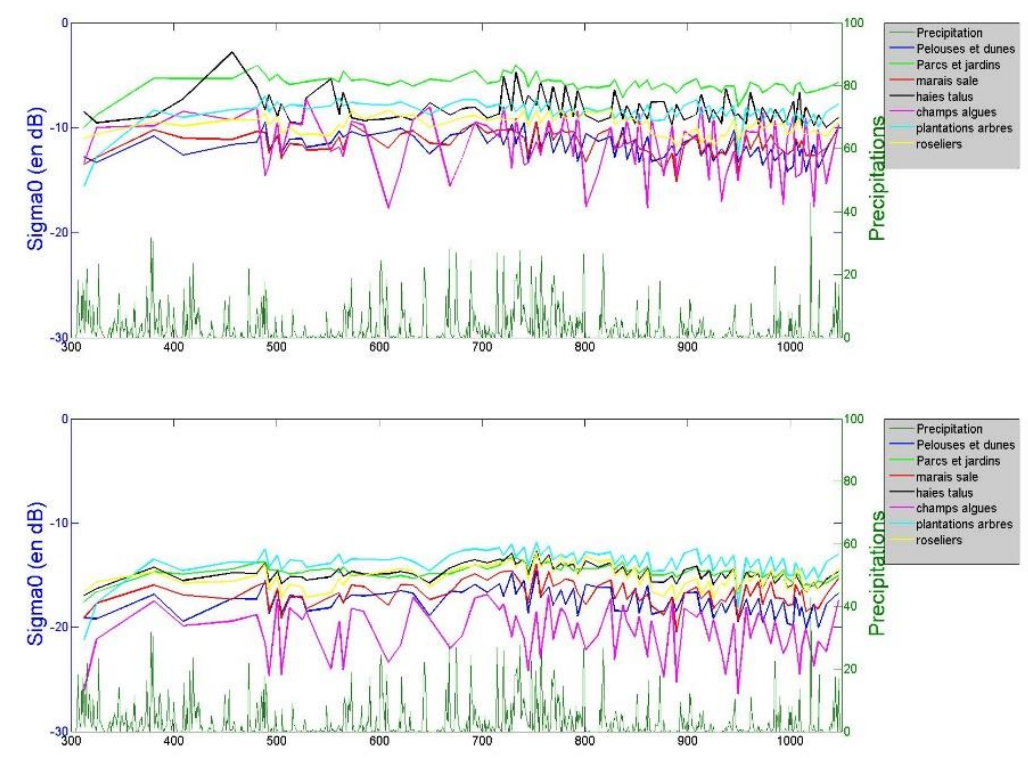

Figure 7. Temporal evolution in VV polarization (top) and VH polarization (bottom) for the radar backscatter coefficient expressed in decibels for the following classes: lawns and dunes, parks and gardens, salt marsh, hedges, embankments, fields and seaweed, tree plantation, reed beds, rocks and cliffs

As concerns the other types of classes, i.e. lawns and dunes, parks and gardens, salt marsh, hedges, embankments, field and seaweed, tree plantations, reed beds, rocks and cliffs, in VV polarization, the parks and gardens had the highest radar backscatter values, whereas in VH polarization, they no longer have this property, and it is the tree plantations that have the highest $\mathrm{VH}$ values throughout the whole period. Moreover, just like for the classes initially analyzed, the evolution is better revealed by $\mathrm{VH}$ polarization than by VV polarization. The only exception is the seaweed field class, the values of which are aberrant as compared to the other classes. This class includes complex systems made up of "submarine" forests, which accounts for the behavior of their radar backscatter coefficient, which is impaired by the presence of water.

For Random Forest Classification of SPOT-6 data (figure 6), the accuracy was acceptable. Confusion matrix indicates an overall accuracy of $86.6 \%$ which is quite acceptable. The Kappa coefficient was calculated from the data provided by the matrix. The value of the latter is 0.74 . These two indices confirm the first observations made on the classified image. The categories "forests", " Hedge and embankment ", " Tree plantation ", " Grassland " have a precision for the director below $60 \%$ indicating that the majority of the pixels are not correctly classified. Conversely, the classes " Seaweed field ", "vegetation-free" have values greater than $90 \%$ for this same indicator. With rates above $80 \%$ for user accuracy, the "lawn and dune" and "salt marsh" categories have a majority of well-classified pixels. Based on comission error, which is the share of pixels that are classified in a different class than the one to which they should belong (Calloz \& Collet, 2001), the fields " Hedge and embankment ", "Moor" and "park and garden" have a rate of more than 60\%, indicating that many pixels assigned to these fields do not belong to this class. For the other classes, the values are greater than $50 \%$ indicating confusion within these classes. 
Contribution of Sentinel-1 Satellite Images to Vegetation Monitoring 15

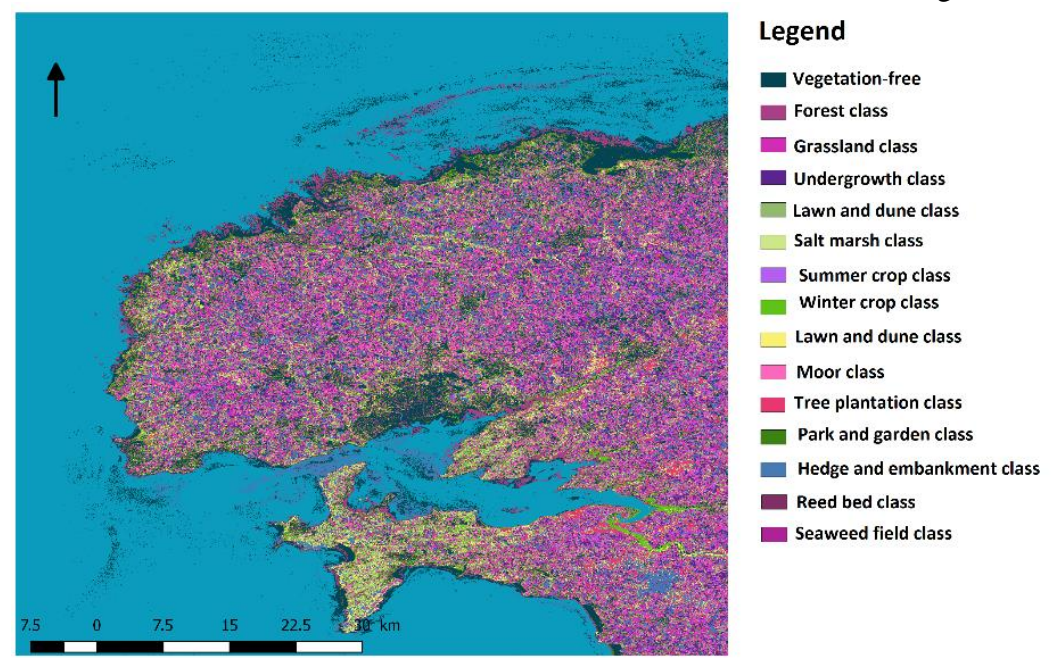

Figure 8. Random forest classification of SPOT-6

The result of Random Forest classification for the synergy method gives more efficient results, an overall accuracy about $90 \%$ and a kappa coefficient of 0.78 .

\section{6- CONCLUSION}

This research allowed us to calculate the interferometric coherence and radar backscatter coefficient of the different vegetation classes in the Pays de Brest in 2015 and 2016, and thus to outline the different temporal profiles. In this respect, we proved the importance of the new series of Sentinel-1 satellite images for the temporal monitoring of the local vegetation and for distinguishing the types of plant land cover in the Pays de Brest due to their significant spatial and temporal resolutions. Moreover, we found that VH cross polarization monitoring is the most reliable for this research Our research was conducted on different plots with summer and winter crops, moors, grassland, forests and undergrowth. We found that there was a correlation between the calculations of the radar backscatter coefficient and the precipitation measurements, especially in VH cross polarization (Figure 6). We also revealed the existence of a correlation between the radar intensity measurements and soil humidity. Thus, the backscatter coefficient may be considered to be suggestive of vegetation development.

Another element that may be considered in order to account for the findings in the graphs could be the object of the frequency of the $\mathrm{C}$ band used by the Sentinel-1 antenna. Indeed, radar bands no longer have the same frequency and therefore they do not penetrate the different vegetation strata.

The different classifications conducted enabled us to assess and compare the methods used. Indeed, this research was a great opportunity to explore new software and define its contribution. According to the findings achieved, we could conclude that the ENVI software remains satisfactory for satellite image processing. As far as free software is concerned, its contribution is more ambivalent. Whereas SNAP did not have very positive results, the QGIS extension is a new and very promising tool. Despite the many difficulties generated by the use of this extension, the two classifications had considerably better results than with ENVI and SNAP. Therefore, this new tool certainly is an asset for the de velopment of remote sensing tools.

Finally, the combination of the three types of data (Sentinel-1, Sentinel-2 and SPOT-6) insures excellent multi-sensor classification accuracy of the recognition and mapping of the main classes of vegetation in the Pays de Brest. The temporal resolution of Sentinel series is therefore a revolution in remote sensing field. 


\section{Contribution of Sentinel-1 Satellite Images to Vegetation Monitoring 16 REFERENCES}

[1] Baghdadi, N., Moinet, S., Todoroff, P., and Cresson, R. (2012). Utilisation de l'imagerie radar Terrasar-x THRS pour le suivi de la coupe de la canne a sucre a l'ile de la Reunion. Rev. Francaise Photogramm. Teledetection 64-75.

[2] Dusseux, P. (2014). Exploitation de séries temporelles d'images satellites à haute résolution spatiale pour le suivi des prairies en milieu agricole. phdthesis. Université Rennes 2.

[3] Fieuzal, R. (2013). Apports des données radar pour l'estimation des paramètres biophysiques des surfaces agricoles. phdthesis. Université Toulouse III - Paul Sabatier.

[4] Floury, N., Le Toan, T., Souyris, J.-C., Singh, K., Stussi, N., Hsu, C.C., and Kong, J.A. (1997). Interferometry for forest studies. In ESA SP, (European Space Agency), p.

[5] Frison, P.-L., Le Toan, T., Fruneau, B., and Dufrêne, E. (2017). Apport des données Sentinel-1 pour le suivi saisonnier de la végétation.

[6] Gosselin, G., Touzi, R., and Cavayas, F. (2014). Polarimetric Radarsat-2 wetland classification using the Touzi decomposition: case of the Lac Saint-Pierre Ramsar wetland. Can. J. Remote Sens. 39, 491-506.

[7] Guerriero, L., Pierdicca, N., Pulvirenti, L., and Ferrazzoli, P. (2013). Use of Satellite Radar Bistatic Measurements for Crop Monitoring: A Simulation Study on Corn Fields. Remote Sens. 5, 864-890.

[8] Hosseini, M., McNairn, H., Merzouki, A., and Pacheco, A. (2015). Estimation of Leaf Area Index (LAI) in corn and soybeans using multi-polarization C- and L-band radar data. Remote Sens. Environ. 170, 77-89.

[9] Inoue, Y., Sakaiya, E., and Wang, C. (2014). Capability of C-band backscattering coefficients from high-resolution satellite SAR sensors to assess biophysical variables in paddy rice. Remote Sens. Environ. 140, 257-266.

[10] Niculescu, S., Lardeux, C., Grigoras, I., Hanganu, J., and David, L. (2016). Synergy Between LiDAR, RADARSAT-2, and Spot-5 Images for the Detection and Mapping of Wetland Vegetation in the Danube Delta. IEEE J. Sel. Top. Appl. Earth Obs. Remote Sens. 9, 3651-3666.

[11] OTUKEI, J. R. \& BLASCHKE, T. (2010), Land cover mapping using decision trees, support vector machines and maximum classification algorithms. International Journal of Applied Earth Observation and GeoInformation, 12S, S27S31.

[12] PATHIER Erwan, Andrea, PERFETTINI Hugo, CAMPILLO Michel, KOSTOGLODOV Vladimir, ROUSSET Baptiste, ROJO-LIMON Graciela, DOIN Marie Pierre, FRANK, William, LASSERRE Cécile, LHOMME Thiphaine., and RADIGUET Mathilde, COTTE Nathalie, WALPERSDORF (2017). Séismes lents et sismicité : exploration dans la subduction mexicaine à l'aide de la géodésie spatiale.

[13] Pottier, E., and Cloude, S.R. (1997). Application of the H/A/alpha polarimetric decomposition theorem for land classification. pp. 132-143.

[14] Prakoso, K.U. (2003). Tropical forest mapping using multiband polarimetric and interferometric SAR data.

[15] Pulliainen, J. T., Engdahl, M., \& Hallikainen, M. (2003). Feasibility of multi-temporal 
Contribution of Sentinel-1 Satellite Images to Vegetation Monitoring 17 interferometric SAR data for stand-level estimation of boreal forest stem volume.

[16] Remote Sensing of Environment, 85, 397-409.

[17] Rodriguez-Galiano VF, Chica-Olmo M, Abarca-Hernandez F, Atkinson PM, Jeganathan C.

Random Forest classification of Mediterranean land cover using multi-seasonal imagery and multi-seasonal texture. Remote Sens Environ 2012a;121:93-107.

[18] Strozzi, T.; Wegmuller, U.; Werner, C.; Wiesmann, A. (2000). Measurement of slow uniform surface displacement with $\mathrm{mm} /$ yearaccuracy. Proc. Geoscience and Remote Sensing

Symposium, Volume 5, Issue , 2000 Page(s):2239 - 2241 vol.5.

[19] Tanase, M.A., Santoro, M., Wegmüller, U., de la Riva, J., and Pérez-Cabello, F. (2010). Properties of X-, C- and Lband repeat-pass interferometric SAR coherence in Mediterranean pine forests affected by fires. Remote Sens. Environ. $114,2182-2194$.

[20] Torbick, N., Chowdhury, D., Salas, W., and Qi, J. (2017). Monitoring Rice Agriculture across Myanmar Using Time Series Sentinel-1 Assisted by Landsat-8 and PALSAR-2. Remote Sens. 9, 119.

[21] Ulaby et al., 1986 F.T. Ulaby, R.K. Moore, A.K. Fung. Microwave Remote Sensing: Active and Passive, vol. 3, Addison-Wesley Publishers, Reading, Mass (1986) 